\title{
National Cancer Program
}

National Cancer Institute

\section{Source}

National Cancer Institute. National Cancer Program. NCI Thesaurus. Code C18893.

Plans and coordinates the national cancer research program, encompassing the programs of the National Cancer Institute, related programs of the other research institutes, and other Federal and non-Federal programs. 